\title{
Short Videos to Communicate Effectively to Engineering Students
}

\author{
Eduardo J. Arrambide-Leal, Vianney Lara-Prieto, Rebeca M. García-García \\ Escuela de Ingeniería y Ciencias, Tecnológico de Monterrey, Mexico.
}

\begin{abstract}
The use of multimedia in education has become a basic tool for educators. As Millennials and Generation $Z$ use technology in their everyday life, the educational model has been shifting towards the use of multimedia and technology to enhance the active learning process.

The objective of this project was to design, produce and implement short educational or instructional videos to present content with a more active approach and measure the impact on their understanding and preference. A video with the content of graduation requirements was produced, shared with 240 seniors of Engineering Academic Programs.

The results show that $97 \%$ of the students liked the video and the way the content was shared and $91.6 \%$ of the students find the video format useful. The results show that the learning process was active and effective. The exit poll also shows that 97\% of the students think that there should be more educational videos on some other processes.

This project included the design, production and implementation of 18 videos. This research describes the approach and impact of using short videos in engineering and transition from a traditional method of sharing content to students to a more active learning environment.
\end{abstract}

Keywords: Educational videos; active and collaborative learning; student engagement; educational innovation; higher education. 


\section{Introduction}

Educational models all around the world are facing the challenges of implementing technology and multimedia in their courses in an effective way. Traditional learning is no longer efficient to new generations. The new educational model at our university will develop competencies and skills through flexible programs, learning experiences that are both interactive and challenging, educational spaces that promote learning, collaboration, and innovation and the use of innovative technology in the teaching/learning process (ITESM, 2020). Professors are transitioning to the new model and it includes the use of technology in the classroom along with all type of communication with students.

Research on educational videos shows the benefits of implementing technology in the teaching/learning process. The use of video may provide a significant means to enhance student engagement and improve student learning (Allen and Smith, 2021). Mitra's study (2010) suggests that the use of video can provide useful material for students to engage with. Video viewing is an activity that promotes learning in an ongoing and highly interconnected process of comprehension (Marshall, 2002). Successful and productive use of multimedia in the classroom has increased dramatically over the last decades due to the growth of technology and more user-friendly tools (Cruse, 2007).

Brame (2016) considers the use of the video as an effective tool in the learning process, highlighting three elements: Cognitive load, student engagement and active learning. Some recommendations are to keep the videos brief and targeted on learning goals, use audio and visual elements to highlight important ideas and use a conversational and enthusiastic style to enhance engagement. Shephard (2003) also suggests that the video clips should be kept short to be more engaging. Studies suggest that a video should be kept at 3 to 6 minutes for it to be effective.

There have been studies that suggest that the use of videos improve effectiveness in communication with students. Li et al. (2016) used online videos for international students at UCB and UO to stimulate students' interest for exploration of library services and resources. On the other hand, Nikolic's study (2015) on the use of online resources in the teaching laboratory shows that such videos were used by a great amount of students to aid their learning process, increase productivity and at the same time, the level of engagement in the lab practice increased. The use of online resources can have a large positive impact on student learning and experience.

The use of videos to share information and engage with students can have notorious advantages. Having access to multimedia gives students control to watch the videos on their own time, pace and even the choice to repeat the segment if needed for comprehension (Shephard, 2003). Online videos are useful tools for students that are visual learners and the 
ones that prefer to watch short clips to engage in a certain topic instead of reading or a traditional lecture (Diwanji et al., 2015).

This study focused on designing, producing and implementing short educational and instructional videos to be shown in the classroom and be shared in multiple platforms and social media. By sharing the contents in a different way than the traditional methods (orally in the classroom or by email), the aim of the study is to measure the impact of the videos as a communication tool and its usefulness from engineering student's perspective.

\section{Methods}

The first step was to define the list of contents that program directors frequently use either in the classroom or with students. During the semester, students can schedule an appointment with the program directors to answer questions about a certain processes. The goal of the project is to produce videos with those contents that are most requested by students so that this information can be shared in a more friendly way, and at the same time, efficiently. Through a strategic planning session with the program directors of Mechanical Engineering, Mechatronics Engineering and Industrial Engineering, the following focus groups were defined: Current students enrolled in the Mechanical Engineering, Mechatronics Engineering and Industrial Engineering programs. 2. Freshmen students enrolled in the Introduction to Engineering course (2011 study plan) or F1001B (2019 study plan). 3. Senior students enrolled in the Introduction to the professional life course (2011 study plan).

Once the focus groups were defined, a brainstorming session with program directors was held. During this session, a list of topics were chosen based on the importance of its content, the frequency of student's appointments in regards to this issue and the order of importance from a program director's perspective. The topics that were selected as priority are: Course registration process, Social Service, International Programs procedure, Final exams, Alumni short videos, Graduation requisites, Available labs at the campus, Academic improvement program, and Student conduct.

The first approach was to design and produce a video on student graduation requisites. All students at our university have a list of requisites that have to be accomplished by the time they finish their last semester. Instead of sharing the information in class (orally) or by email, the approach was to share it with a video. All the requisites were included as part of the script and a program director explained this while being filmed. Figure 1 shows a screenshot of the video with the format that was used. The content was shared with a casual tone of conversation and an enthusiastic style to enhance engagement.

Once the video was edited, it was shown to 240 students in the Introduction to the Professional Life course from the Mechanical Engineering, Mechatronics Engineering and 
Industrial Engineering academic programs in the January-May 2019 semester. All students have to enroll to this course during their last semester. The video was shown during the class and also shared in the academic program portal (Blackboard) as well as in closed groups on Facebook. The intention of sharing the information online is to offer students the option of watching the video whenever they want throughout the semester. In addition to the institutional email, these two plataforms are the tools that are mostly used to share information with our students. Figure 2 shows evidence of the implementation of the video.

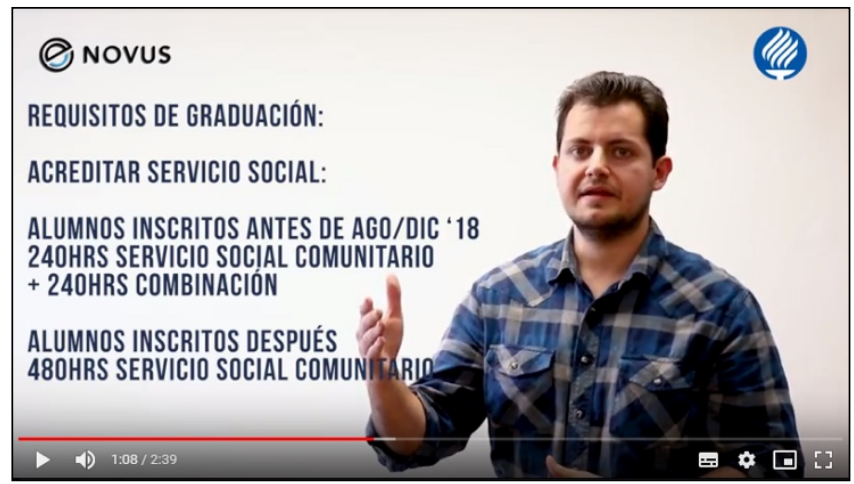

Figure 1. Graduation Requisites Video
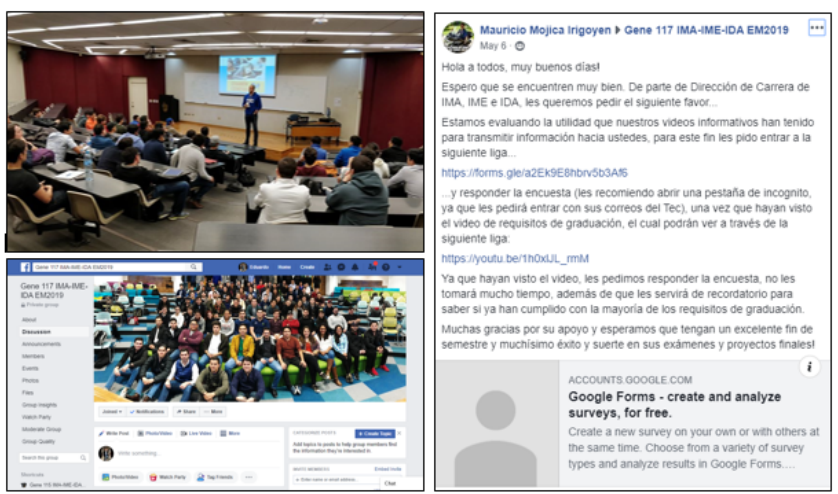

Figure 2. Implementation of the video in the classroom and closed groups on Facebook.

A Google Forms opinion exit poll was created and used to get information from students in regards of the video approach, the way it was shared and the interface that was used. This information will be helpful to verify with the students if they approve the approach and also to determine if they prefer the video format rather than a traditional method. 


\section{Results and Discussion}

As mentioned before, an opinion exit poll was applied to 240 students in order to measure the impact of the video. It was our interest to know if the short video was helpful and if students would prefer this format or a traditional method, such as explanation in the classroom with a PowerPoint presentation or an email. Out of the 240 students, 178 completed the survey. This represents $74 \%$ of the graduation candidates for the five academic programs (IMAMechanical Engineering with minor in Industrial Engineering, IME- Mechanical Engineering with minor in Electrical Engineering, IDA- Automotive Engineering, IMTMechatronics Engineering, IIS- Industrial and Systems Engineering). From the exit polls, $77 \%$ of the responses were from male students while $23 \%$ were from female students. Figure 3 shows the sample distribution taking into account engineering discipline. The representation of the student population in the survey makes sense as Industrial Engineering is the biggest program out of the 5 academic programs.

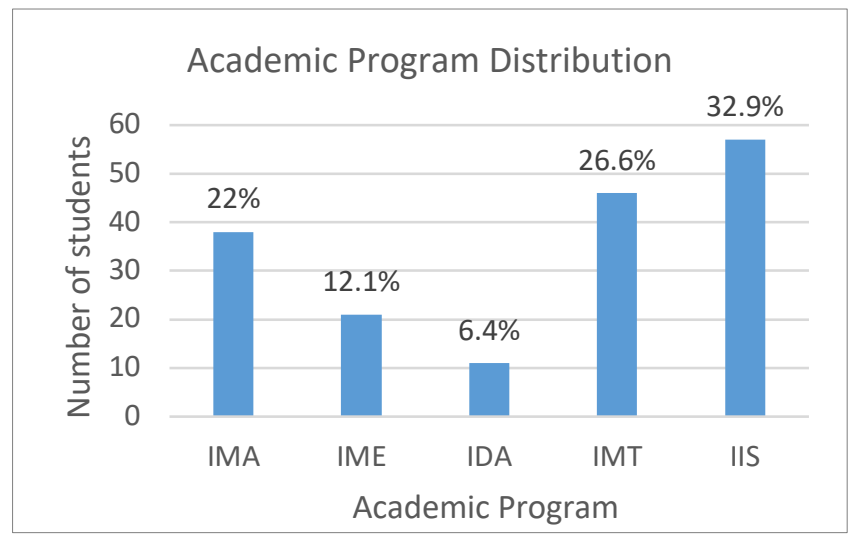

Figure 3. Sample Distribution

According to the opinion polls, $97.2 \%$ of the students liked the information that was presented on the video. As it can be observed in Figure 4, 91.6\% of the students find the video format useful. Students were asked to evaluate on a scale from 1 to 10 , where 10 is the highest and 1 the lowest, how much they learned about graduation requisites with the video format. It was interesting to see that $87.3 \%$ of the students selected a scale of 8 or above. $39.3 \%$ of the students chose the highest score. Figure 5 shows the results for this question and the distribution of the results. Apart from the video, it was our interest to see if students would prefer to have more educational videos made for other univeristy processes. Figure 6 shows that $97.1 \%$ of the students think that there should be more videos for other topics and processes. Results confirm that students prefer the use of multimedia for this type of information. 
As a discussion, it was interesting to see on the exit poll that there is a 2 to 1 ratio on the student's preference in regards of the video approach versus the traditional explanation by a professor in the classroom. Future work in this study includes investigating the preference and efficiency of the different platforms where these educational videos can be shared. The poll's results reaffirm the main goal of the project: create and implement short videos in order to communicate effectively and at the same time, enhance comprehension, and engage with students.

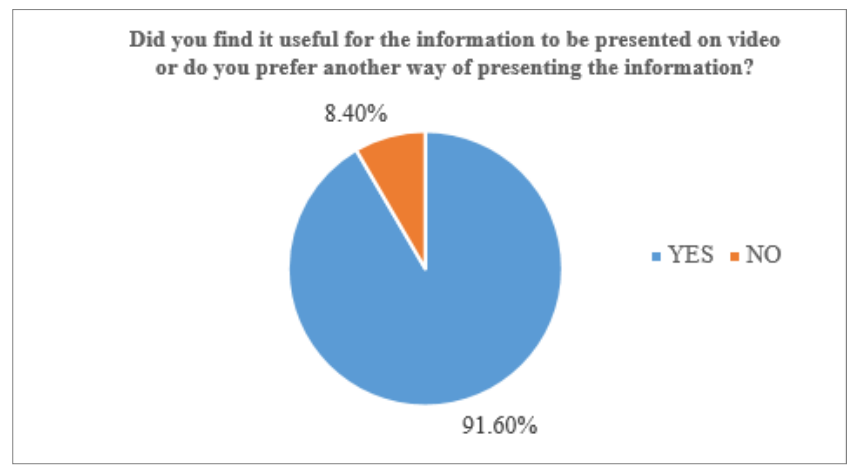

Figure 4. Results on the video format

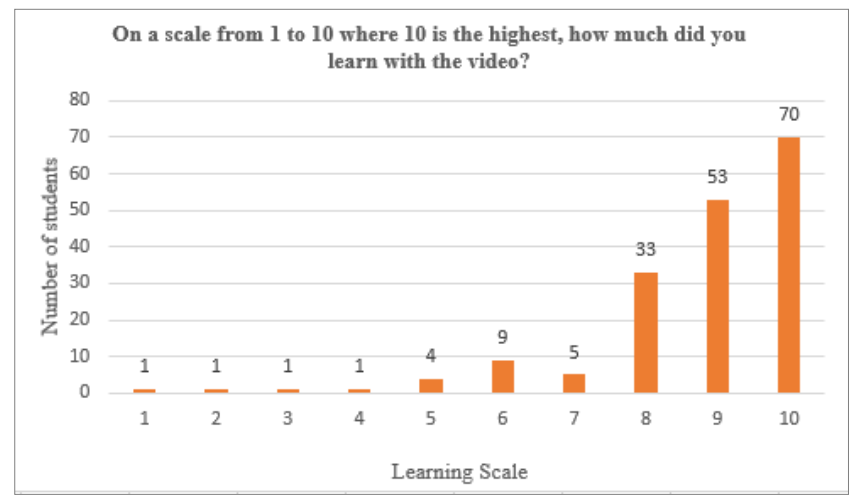

Figure 5. Learning outcome with video format 


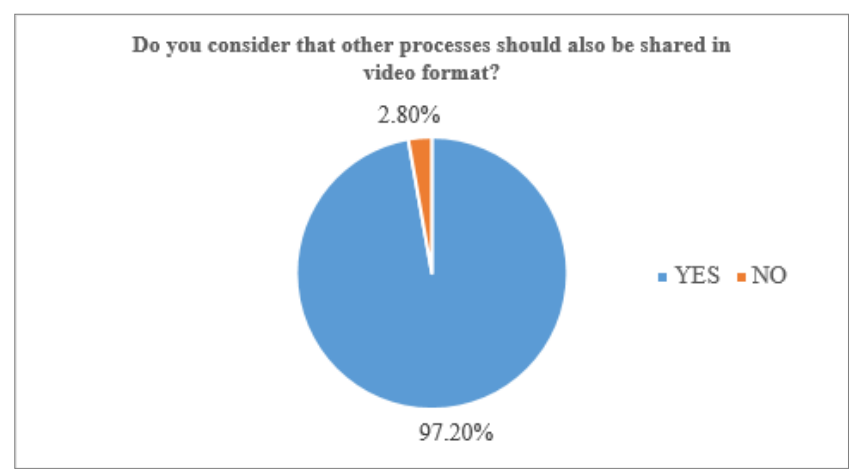

Figure 6. Results of student preference for more videos of other processes

Once the results were obtained and the team confirmed that our students prefer to receive information in a video format and find that approach useful and effcient, the following videos were produced and implemented: Virtual Lab Tours, Lab Safety Rules, Lab Practices, Graduation requisites, International Programs, Course registration process, Final Exams, Course drop out process, Alumni testimonials, Students testimonials, Block F1001B (Academic Regulations, Services and Processes).

The impact of sharing these videos in the academic program portals is shown in Table 1 . Around 2,662 students have the videos available at the portal and have access at any time. This will benefit students as the information will be available online, and if there are further questions about a certain topic, students can request an appointment with the program director. The number of student appointments in regards of the content that was covered with videos, is expected to be reduce. This would be also interesting to measure for future work.

This project also produced videos that were implemented nationwide as part of the new educational model in the F1001B block. Around 390 professors in all of Mexico's campuses were able to use the educational videos with the 5,571 engineering freshmen students. 
Table 1. Impact of Educational Videos

\begin{tabular}{lc}
\hline Academic Program & Number of Students \\
\hline IMT- Mechatronics Engineering & 652 \\
IMA- Mechanical Engineering with minor in Industrial \& Systems & 550 \\
Engineering & 300 \\
IME- Mechanical Engineering with minor in Electrical Engineering & 180 \\
IDA- Automotive Engineering & 1150 \\
IIS- Industrial \& Systems Engineering & 5,571 students \\
Modeling of Engineering and Science- Module Zero (Nationwide) & \\
\hline
\end{tabular}

This project included the design, production and implementation of 18 videos. This study analyzed the impact of one of them focused on last-semester students. A limitation of this study is that the survey was conducted on groups where the professor was the researcher asking and might have a positive bias. Future work considers contemplating freshmen students, applying the survey to different groups where the professor is not the researcher.

\section{Conclusions}

Educational models are shifting from the traditional teaching format to an active learning environment. One approach to achieve active learning and student engagement is with the use of short videos that will connect with our new generations. The use of short educational or instructional videos with a casual conversational approach connect with new generations. Millenials and Generation $\mathrm{Z}$ students are used to technology and this approach engages them with the content and their learning style.

This study shows that students connected with the video, they liked the video format and they learned in a more active way. Students were engaged with the videos and suggested that more contents should be available in this format. Also, it was interesting to see that students prefer multimedia rather than a traditional method (email or oral method). Educators have the challenge to transition from a traditional way of teaching to an active learning approach and the use of technology will improve student's interest and engagement.

\section{Acknowledgments}

The authors would like to acknowledge the financial support of Writing Lab, Institute for the Future of Education, Tecnologico de Monterrey, Mexico, in the production of this work. 


\section{References}

Allen, W.A. and Smith, A.R. (2012). Effects of video podcasting on psychomotor and cognitive performance, attitudes and study behavior of student physical therapists. Innov Educ Teach Int 49, 401-414.

Brame, C. J. (2016). Effective Educational Videos: Principles and Guidelines for Maximizing Student Learning from Video Content. CBE—Life Sciences Education, 1-6

Cruse, E. (2007). Using Educational Video in the Classroom: Theory, Research and Practice Multimodal Learning Styles Dual-channel Learning Motivation and Affective Learning.

Diwanji, P., Simon, B.P., Maerkl, M., Korkut, S. and Dornberger, R. (2015). Success Factors of Online Learning Videos. International Journal of Interactive Mobile Technologies 9(4): $125-132$

ITESM, Strategic Plan $2020 . \quad$ [Online] Available: http://sitios.itesm.mx/webtools/planestrategico2020/publico/EN/index.html, Accessed: 18-Jun-2019

Li, X., McDowell, K. and Wang, X. (2016). Building bridges: outreach to international students via vernacular language videos. Reference Services Review 44(3): 324-340.

Marshall, J.M.(2002). Learning with technology: Evidence that technology can, and does, support learning. White paper prepared for Cable in the Classroom. San Diego State University.

Mitra, B., Lewin-Jones, J., Barrett, H. and Williamson, S. (2010). The use of video to enable deep learning. Research in Post-Compulsory Education 15(4): 405-414

Nikolic, S. (2015). Understanding how students use and appreciate online resources in the teaching laboratory. International Journal of Online Engineering, 11(4): 8-13.

Shephard, K. (2003). Questioning, promoting and evaluating the use of streaming video to support student learning. British Journal of Educational Technology, 34(3): 295-308. 